\title{
Drinking up endings: conversational resources of the café
}

\section{Eric Laurier}

Institute of Geography, School of Geosciences, University of Edinburgh Edinburgh EH8 9XP 


\begin{abstract}
A first theme of this article is the abiding relationship between the café and conversation. A relationship which begins with Habermas's emphasis on political debate in early modernity and continues to more contemporary studies of the service encounter. A second theme is conversation analysis and its concern with closing sequences of phonecalls. Drawing on the work of Goodwin I examine the importance of gesture and materials in closing sequences in one of the many conversations we have off-line. Given that it is the café the bodily movements of speakers are in and around both the architectures of the café and, centrally, the drinking of drinks. An illustrated transcript of two co-workers closing their conversation, and stay, in café is analysed to flesh out the argument over the resource that drinking provides for talking together.
\end{abstract}

\title{
Keywords
}

Cafe, conversation, closing sequences, gestures, drinking

Note for the final draft illustrations will be provided on separate sheets. They are integral to reading the text so have been left in for this first reviewer's draft. 


\section{The return of café society}

In the USA and the UK, cafés, which had been in a long run decline over the past forty years, have returned with, not so much a vengeance as, a more or less happy acceptance. There has been some protest, Starbucks with its global reach and ambition has become a conspicuous target, while simultaneously requiring a rethinking of what dangers multinational companies pose (Raffel, 2004). Even though it is in the same sector as Macdonalds and has had the honor of displacing it as a target for brick-lobbing activists, its employment conditions, the quality of its product and moral concerns are of quite a different order (Baggini, 2004). As Raffel (2004) argues our concerns over Starbucks are to do with its steady spread and its simulation of the place-specific qualities of its Milanese and Seattle originals. What the return of cafés in general, rather than the rise of Starbucks in particular, have raised for us, as a society, are questions of sociability, civility and conviviality in the public sphere. Questions all the more pressing because a number of other institutions such as the Scouts, the church, voluntary organisations and various sporting leagues, that were once at the heart of our communal lives are in decline (Putnam, 2000). In the face of this decline the return of café society promises a cultural cosmopolitanism and creativity of the kind witnessed in Vienna or Paris in the middle of the $20^{\text {th }}$ century or, indeed, London in the $18^{\text {th }}$ century (Cowan, 2005; Ellis, 2004; Van Horn Melton, 2001)? In the UK cafés raise these questions over the state and fate of public sphere by way of contrast with that longstanding place of encounter and dialogue with friends, allies, strangers, enemies and familiars - the pub. Coffee replaces alcohol, the daytime the night-time, the cup for the glass, the counter for the bar, the barista for the bar maid, bawling babies for brawling drunks. Yet for all their differences so much is shared: expectations of conviviality, the formation of distinct crowds, shelter from the rain or the hot sun, the recognition of regulars, the enjoyment of the presence of others and, of course, the centrality of conversation sometimes domestic, sometimes political, sometimes with matchless wit, sometimes with life-dimming dullness.

For theorists and historians of modernity, most notably Jurgen Habermas (1989), the city and the public sphere coffee houses have long been of interest as sites without which new forms of encounter, dialogue and social mixing we now take for granted would have been impossible (Laurier \& Philo, 2007). Central to his account of the rise (and fall) of the public sphere, Habermas treated the coffee house as the place where the orations of politicians (see Ellis, Remer this volume) would be digested in dialogue with a pie and a pint of stewed coffee. The coffee houses were places tied into the society of letters, and in very practical ways, since the newspapers of the day had postboxes inside a number of London coffee houses. Not only dialogues between members of the public occurred in the coffee house, letters to the editor on matters of politics could be written and posted. While many of Habermas's causes of the decline of public life have continued, one wonders how Habermas would assess the return of public lectures on science in cafés in the UK through 'Café Scientifique' (http://www.cafescientifique.org/) and a desire to disseminate philosophy outside the university system in the USA through the 'Socrates Cafés' (Phillips, 2001). In the new cafés in the USA and UK newspapers are almost ubiquitous and so, throughout the day, they are being read in public rather than in the seclusion of kitchens and sitting rooms. Indeed, there are still particular cafés and bars where journalists, writers and others in the creative and media industries gather (Pratt, 2002) or that host an array of 'scenes' from the arts to the commercial (Blum, 2003). 
Where Habermas placed his emphasis on the emergence of a bourgeois public sphere, Ellis (2004) through more careful historical documentation shows that at their outset coffee houses were as renowned for their rumbustiousness and criminality as their polite and political debate over matters of the day. If, and when, the debating, opinion-forming public with its members were formed in coffee houses, they were one collective amongst many others that dwelt therein. In recalling that from the outset cafés were not quite the public sphere Habermas would have liked them to be, we can at the same time wonder if in exceeding his vision they supplied the city with a less limited if also less politically pointed conviviality. As Amin and Thrift (2002) note places like cafés can not be marshaled into replacing certain forms of political activism that are necessary to local democracy and political participation. Not least because of the limits of Habermas's idealization of a conversational mode of politics which misses the necessity for oratory and speeches (see Remer this volume). From the perspective of the everyday life of the city cafés should not be principally places for political debate since this would kill the very open-ness that is at their heart.

\section{What happens in cafés?}

If, whenever housewives (sic.) were let into a room, each one, on her own, went to some spot and started to clean it, one might conclude that the spot surely needed cleaning. On the other hand, one might conclude that there is something about the spot and about the housewives that makes the encounter of one by the other an occasion for cleaning, in which case the fact of the cleaning, instead of being evidence of dirt, would itself be a phenomenon. P168 (Garfinkel, 1986)

To paraphrase Garfinkel \& Sacks:

If, whenever people were let into a city street, each group, on their own, went to a particular cafe and started to drink, one might conclude that the café surely attracted drinkers of their brand of coffee. On the other hand, one might conclude that there is something about the cafe and about the customers that makes the encounter of one by the other an occasion for drinking, in which case the fact of the drinking, instead of being evidence of thirst, would itself be a phenomenon.

While Habermas and others have been concerned with the public sphere, students of language and social interaction have studied the café predominantly in terms of service encounters. One reason for this persistent focus is that serving customers at the counter or at their tables is a recurrent activity in cafes. What occurs in and around the serving of customers in the café is so diverse that one has only elements of it analysed by various researchers. As noted earlier Habermas concentrated on political deliberation, Oldenberg (1997) on neighbourhood sociability and Wakeford on the local embedding of global technologies (Wakeford, 2003). While I will concentrate on conversation later in the article, it is not only conversation that happens therein. During ethnographic studies (Laurier, 2005a; Laurier, 2005b) as part of a larger project on cafés and public space we listed all manner of activities, to list a small sample here: a woman writing a birthday card, a couple breaking up, colleagues assembling a website on a laptop, a birth group with their newborns discussing sleep patterns and breastfeeding, a salesman selling an insurance policy to a customer, a student annotating his textbook, tourists planning their day abead, an old man reading a newspaper by bimself, an old woman doing word puzzles by herself, two couples resting between shopping for clothes, a grandmother coloring in pictures with her grand-daughter, three women discussing their relationships with the men in their lives, three friends watching the street out the window, a 'big' man observing the other 
customers, a young couple rolling a marble back and forth over their table, a Christian group meeting up before going to church.

In amongst this incredible diversity of activities, there are, nevertheless, recurrent activities in the café which are less about the service than the custom. They are relatively few in number and so glaringly obvious that we tend to treat them as too trivial to be worth further examination:

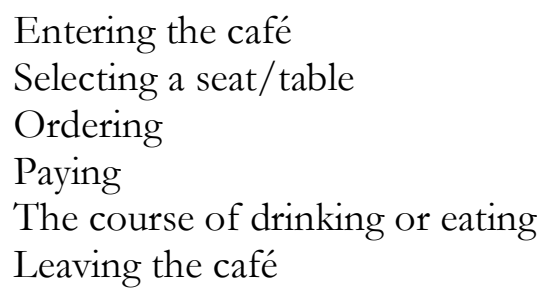

Listing them in this way provides a minimal reminder of the sequence of activities that constitute a café visit. In its starkness it is at odds with the elaboration of the vitality and centrality of café life made by Habermas and others. What will enliven this bare list here is turning to how these activities actually happen as orderly, reasonable, habitual and apprehensible courses of action by customers. When we shift to these quite ordinary things and try and describe them more clearly in terms of how they are done, then we come upon some quite wonderful 'common things' (Perec, 1999). My purposes here are to elaborate how one of these recurrent features of the café both becomes a resource for and is organized by customers speaking together in cafés.

Having noted earlier that making conversation with others is not a prerequisite of dwelling in cafés, like many fellow researchers of ordinary language I am nevertheless deeply interested in the organization of conversation as it is manifest in cafés. To be so interested is to approach the particularities of what we say and how we say it that, to borrow phrasing from Mike Lynch, explodes 'Conversation' into numerous local complexes of activities (Lynch, 1993: 281). With such a shift of perspective in mind the idea that conversation can be an end in itself robs our talk not only of its purposes but also of its pleasures and its sufferings. Consider:

'I want to have a conversation with you.'

'About what?'

'I just want to talk'

'Uh oh! Am I in trouble?'

If conversation were an end in itself the topic wouldn't matter, the wit, sympathy or intellect of your conversant would be irrelevant. What conversation, if it is not an end in itself, can do, is be used to do endings in itself. Hold on a moment, surely we might be 'just talking?' Even here such a description of what we are doing would be the beginnings of marking out that it's not relevant to a third party who is asking 'what are you doing?' in ways that might raise suspicion over those two others being up to something. So to try and say in ordinary conversation that talk is an end in itself raises our suspicions from the outset. We might instead treat ordinary conversation as the beginning of our inquiry.

Certainly, then, ordinary language is not the last word: in principle it can everywhere be supplemented and improved upon and superseded. Only remember, it is the first word. (Austin, 1956-7: 7) 
Where ordinary language philosophy marks out a distinctive departure from and return to scholarly topics, and, significant problems that have motivated and beset philosophy (Austin, 1956-7; Cavell, 2002), conversation analysis (CA) has had a similar relationship with the social sciences and linguistics (Lynch \& Bogen, 1996; Schegloff, 1992). Conversation analysis has developed in a number of directions since its inception by Harvey Sacks in the 1960s (Luff et al., 2000; Lynch, 1997; Schegloff, 2007; te Molder \& Potter, 2005). Some of these have tended toward a form positivistic inquiry losing sight of CA's responsiveness to abiding topics such as observation, reason, social order etc. while others retain the sense that CA like ethnomethodology need not imagine or proceed as if it were the true science of the social sciences, or, indeed, any form of science. Thus, the uptake of Harvey Sacks's lectures has also been similar to that of Austin's ordinary language philosophy which has become the basis of a branch of linguistics (Levinson, 1983) while at the same time providing the underpinnings for work like Stanley Cavell's (2005) which is sometimes at odds with ordinary language as object of scientific inquiry.

Sacks, and others in CA, listened to tape recordings of the openings and closings of phonecalls to examine elements of how we begin our encounters with more than greetings and end them with more than partings (Schegloff, 1972; Schegloff \& Sacks, 1973). In intimately examining closings, they show us how there is other work involved: for instance, in concluding a topic we are providing a point in the conversation where we could begin to say our goodbyes. Moreover CA has documented a great deal of the specificities of speaking on the phone compared to gossiping at the front door of one's house (Laurier et al., 2002) or prosecuting and defending in court (Lynch \& Bogen, 1996) or in the night's work of discovering a pulsar (Lynch et al., 1983). It is no accident that the phonecall has been one of CA's central phenomena since the phone call is one of 'Sack's glosses'. The phonecall is a perspicuous setting that 'the analyst looks to find, as of the haecceities of some local gang's work affairs the organizational thing that they are up against and that they can be brought to teach the analyst what he needs to learn and to know from them ...' (Garfinkel \& Wieder, 1992) p186. The organizational thing that can then be offered back to the local gang in quite unexpectedly detailed descriptions of numerous local accomplishments. The organizational thing that Sacks was pursuing was, of course, turn-taking as one of the machineries for organising conversation. In terms of being an occasion the phone call has those exceptional qualities of talk constituting its openings and talk constituting its closings. Where ever CA has shifted to other ways of talking together than the phonecall it comes up against such things as looking and gesturing where the gestures are arranged for the looks and the looks themselves can be gestures, the arrangements of people around things that they are attending to, the rhythms of tasks (from hammering nails to performing surgery), the handling of tools, furniture, clothes etc. and more (Goodwin, 2007; Livingston, 1987; Sudnow, 1972). Of particular pertinence to how customers dwell in cafés, a number of studies have focused on how talk organizes and is organized by locomotion of speakers through, by, away from and toward architectural features. This avenue builds, firstly, on Christian Heath and Dirk vom Lehn's (Heath \& vom Lehn, 2004) museum studies wherein they have looked at movement around the museum and its exhibits. Secondly Lorenza Mondada (forthcoming-a) and her colleagues (Balthasar \& Mondada, 2005) have been analyzing the spatial configuration work of speakers as guides and tourists involved in walks in the city and as flatmates moving in and out of the kitchen, dining room and halls in a domestic space. And, finally, there have been a number of studies of navigation through libraries' heavily textually textured architectures as part and parcel of searching for books (Carlin, 
2003; Crabtree, 2000). These studies of locomotion and talk bear some resemblances to cafés $^{1}$ in that there are all manner of intriguing ways that talk's work attends to, utilizes, arranges and transforms the trajectories and orientations of bodies of mundane architectural practices. What is pertinent to ending the occasion is that entire conversations or merely topics can be brought to a close by persons using their arriving at or leaving of a particular room, exhibit, desk or area of shelved books.

What then does the café as an environment oriented to drinking, with typical seating arrangements, architectures, ambiences and furnishings bring to how we talk to one another? There is not the space in this article to consider all the possibilities but given that we have already raised the matter of closing phone calls, how do we finish up our time sitting together in the café? Finishing our visit to a café is about more than the earlier mentioned materials and embodied actions, it requires us to achieve the ending as an appropriate accountable part of the occasion that it is. In Schegloff \& Sacks' (1973) paper 'Opening up closings' having closely described the technical aspects of producing closings in telephone conversations, they return, in capital letters, to what kind of other less technical thing is being ended:

'the possible need for preparing them, has to do with the OCCASION'S ending, and it is a part of conversation that the occasion may be ended. It is by way of the use of the closing the conversation for ending the occasion that the use of a section to end the conversation may be appreciated, in a way similar to our appreciation of the use of a snack to end an evening or get-together. Schegloff \& Sacks 1973 (Schegloff \& Sacks, 1973)

Accepting the point that the phonecall is a member of a wider set of occasions there is, then, a reminder that other resources such as snacks or, of course, drinks, can be brought into play when we are ending occasions.

\section{The Café Again}

At the heart of the café, is the activity which is often remarked on and then quickly passed over in favour of something more apparently profound, the drinking of drinks. Drinking, be it of beer or coffee or milk, keeps our mouths occupied during all manner of sociable occasions where those mouths are also and otherwise engaged in talking. As Simmel remarked it serves as an alibi for conviviality, we are at the café to drink coffee and not to hang around with other people for the pleasure of hanging around with other people. Though as we've noted in list form already so much more occurs in the café than conviviality. In terms of the coffee drinking itself, from a slightly different perspective comparing cappuccino to a once generic 'cup of coffee' in the UK and USA, Blum (2003) contemplates how in drinking a cappuccino in a café we are able to feel cosmopolitan ${ }^{2}$. Many writers have remarked on the stimulant qualities of the caffeine for enlivening conversation (Cowan, 2005; Ellis, 2004).

What if the caffeine is not as important as the paraphernalia and the embodied practices of drinking? In his Lectures (1992) Sacks teases out various ways in which cigarettes

\footnotetext{
'For more detail see the project website: http://web.ges.gla.ac.uk/ elaurier/cafesite/

${ }^{2}$ In a short editorial piece Stanley Fish contemplated with a hint of self-mockery the shift in service labour division involved from the 'cup of coffee' to the contemporary espresso and milk cocktails (Fish, 2007).
} 
allow for much more than getting a puff of nicotine. Firstly that they allow for eye-to-eye contact whether between the unacquainted when trying to pick one another up or between those already acquainted. Secondly, how smoking defuses silences, allowing people to stand together saying nothing without the absence of talk meaning anything. Where as he puts it 'the development of the ability to have a pause in a relationship is crucial' (Sacks 1992: 50). Thirdly, when people are smoking cigarettes its allows them to move more freely. In getting a light they can bend their heads toward the other and look up at them which, Sacks notes, in Western cultures can be flirtatious. With a cigarette in their hand they can move it to their face allowing the person they are with to follow the cigarette to their face and thereby a dance of looks intended and unintended can follow.

You will have likely guessed by now that similar playful possibilities for mutual monitoring of talk and gesture exist when we are drinking together as when we are smoking together. Our interest is in how this will come together with finishing a visit to a café. To give us a better appreciation of how talk and drinking can be used to end the occasion of a public morning coffee together we can turn to some illustrated transcripts of two women talking in a cafés. They were mid-morning customers on a break from their workplace. When we join them they have been drinking for about ten minutes. As we so often do with our colleagues they have been talking about one of the other people that they work with. The woman with her back to us (B) has just finished talking on her topic, prefacing her winding up what she has been talking about with 'at the end of the day'. After a pause, in response the woman facing us $(F)$ then adds:
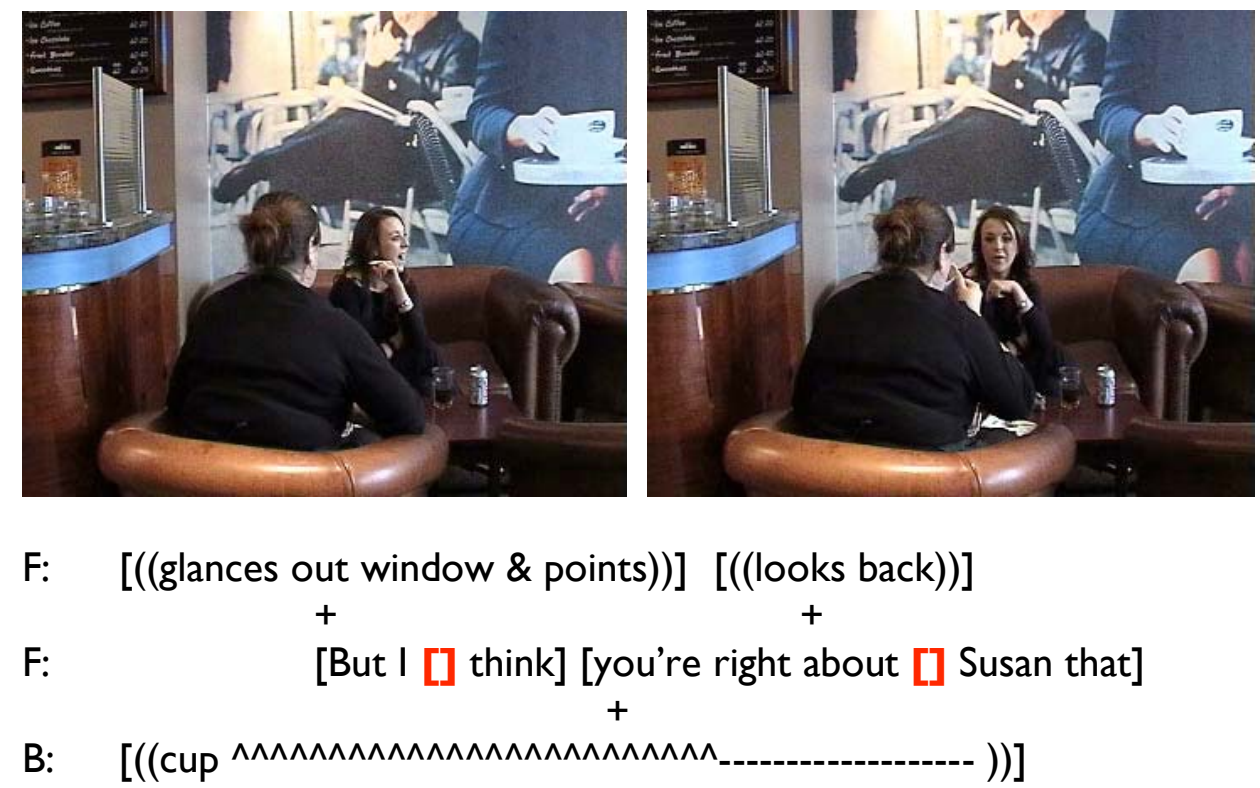

Here is where the ending of the coffee break begins, though not at this precise moment since of course the progress of one another's drinking is visible to both drinkers. Having offered the end of her story with 'but at the end of the day', B lifts her cup and then adds

\footnotetext{
${ }^{3}$ With only one camera we have no access to $B^{\prime}$ s facial expressions, though we can still catch her cup and head movements. Researchers using video have begun to pioneer multiple perspectives on the action (Mondada, 2006; Mondada, forthcoming-b). However we have to be wary of the illusion that audio visual records have escaped their status as records and thus being renderings of original events, to become the event as it happens. The record is inevitably incomplete, partial and past tense and we analyse video through what is showed itself to observers at the time and where their and our attentiveness and project's shape such a grasp. For more on this point see (Laurier \& Philo, 2006; Livingston, 1987; Raffel, 1979).
} 
that extra tilt (see the second still above) which while mechanically necessary also makes it visibly the last sip (just as it would be for a glass of beer etc.). Here, then, are two of the criteria in place for a possible completion of their coffee break but if we look at the table $\mathrm{F}$ is not even half way through her glass of coke.

Nevertheless, if we examine the talk and looking that happens at the same time the coffee cup starts on its rise towards B's mouth. There is the 'but' that F [looks away] on before returning to [look toward] B. The 'but' recognises that B has made some moves to end their conversation, even as it warns that $\mathrm{F}$ has more to say and that more ought to be said on the matter. The [glance out the window] preceding the [look toward] nicely accentuates the 'you' of 'you're right'. Already then what the environment of the café offers to speakers are surroundings that they can quite justifiably glance at while they are talking. Thereby these looks are not treated as avoiding the eyes of the other person (though there are limits on such glancing around before we begin to seem distracted). Rather, the glance can be used to then produce, in its timing with what $\mathrm{F}$ wants to say, as having looked away at 'but' when F argues to say more on the topic. Then, when F looks back it is timed to allow her both to emphasize and watch how B responds to what begins as support and perhaps praise for an earlier evaluation of one of their colleagues by B that 'she's too friendly'. A third feature of the look is that it monitors the rise, sup and return of B's coffee cup and thereby allows the supping's ordinary course to guide the production of F's turn. While this may seem speculative, if we look at the transcript above, the cup rises with one possible turn unit and, if we look at the transcript below, falls on F's next turn. F nicely extends her 'too' as a possible turn completion which B takes up just as her cup touches back down on to its saucer. The organization of the drinking, in other words, supplies organizational resources to the talk.
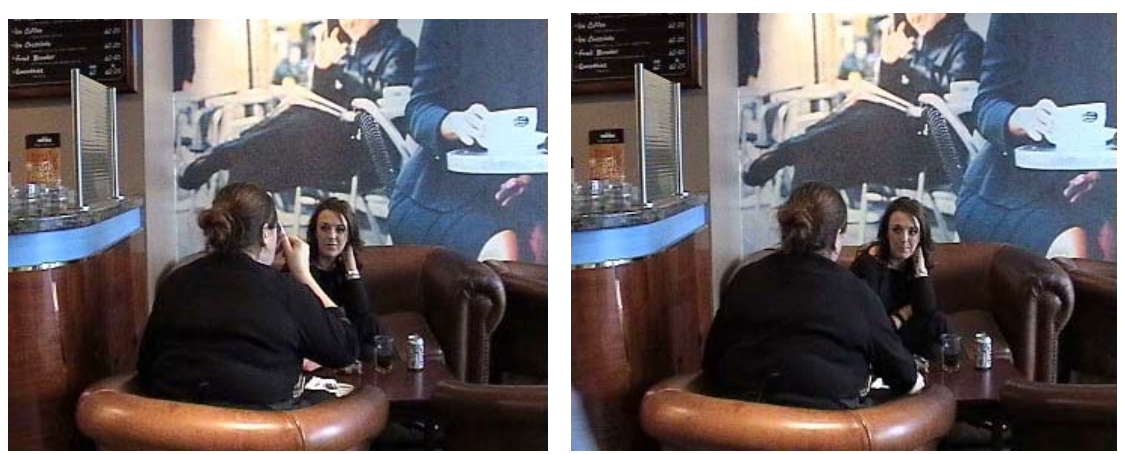

F: Just [] I think she's just too friendly

B: ((cup -----vvvvvvvvvvvvvvvvvvvvvrvvvvvvvv))

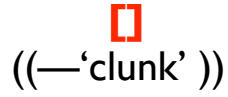

F: I mean [too::.:.:.:.:.:

B: $\quad$ [And she just] doesn't want to.

F: $\quad$ Laidback

B: Isn't into it. 
The last sip nevertheless brings in the relevance of finishing the coffee break and a few remarks later B looks toward her wrist and this time we see a second pair-part gesture produced by $\mathrm{F}$ in response when she brings her wristwatch into play, twisting it around and looking at it:
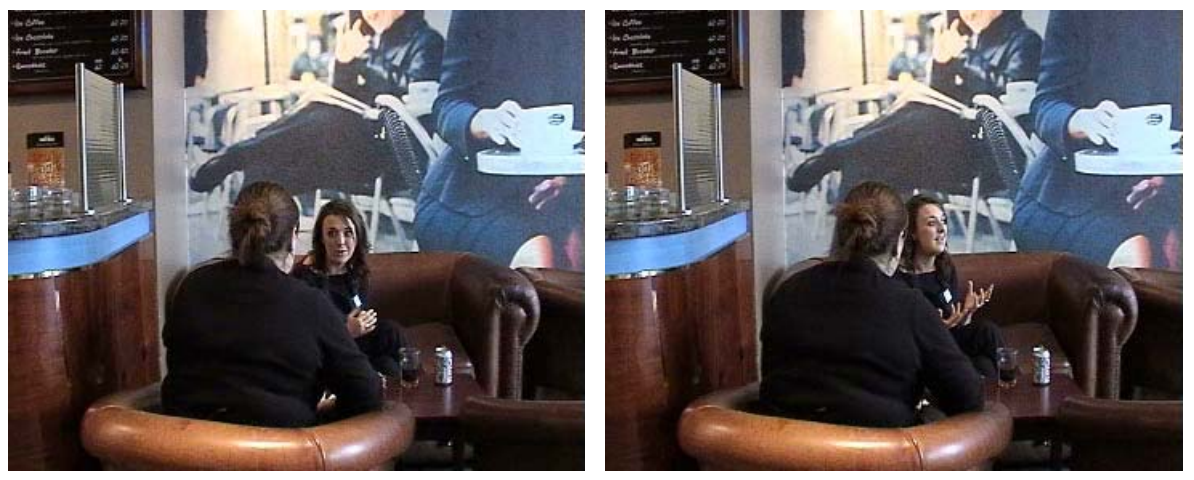

\section{F: Do you [] know what I mean. I need [] tuh. I need [tuh get a job out[ $+$}

B: $[(($ looks at watch $))]$ We need to

leave

\section{F: $\quad$ Yeah}
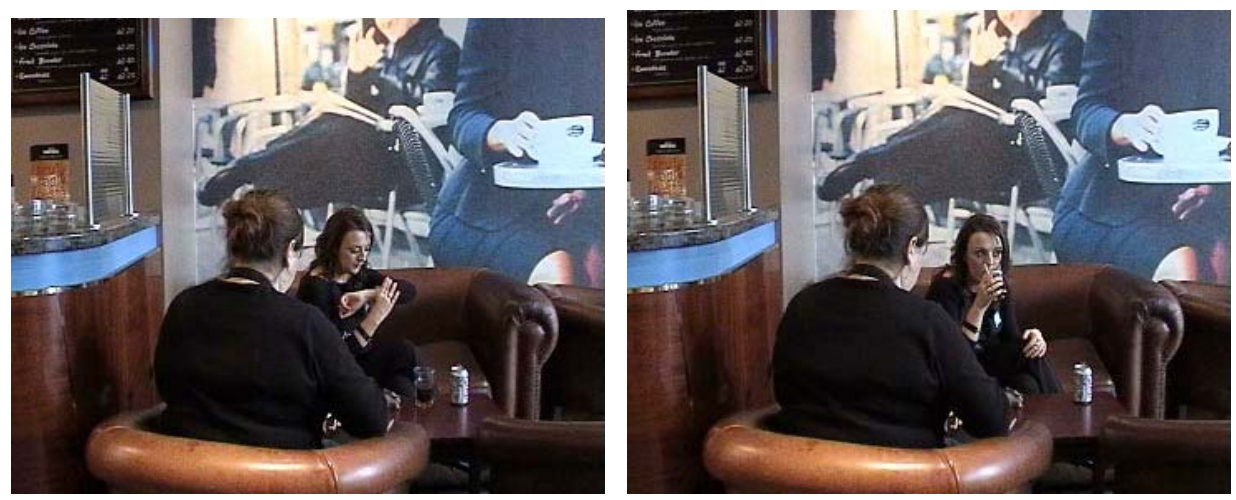

\section{F: ((moves her arm and glances at watch [], then drinks)) Which is eh (([]drinks))}

\section{B: But that's maybe}

In the above transcript $\mathrm{B} \& \mathrm{~F}$ are not bringing their wristwatches into consideration ('mine's a Rolex'), they are topicalising the time where for the two of them on a coffee break, the break has clock-marked features. Doing so in silent yet visible ways unavailable during phonecalls. It could be that on checking their watches they discover that they are late and leap up immediately. What in fact happens is that $\mathrm{F}$ takes a visibly quick drink from her glass compared to B's earlier slow sup, or the paused glass we will see later. By drinking as the immediately succeeding action F orients to a speeding up of their drinking. In other words to make it to the end of their drinking in time for the end of their marked time. The pace of their refreshment has been increased.

After this quick sip F makes a charming and classic gesture of having finished with her 
drink even though the glass is not empty when she puts it back on the table: she pushes it away from her. The glass ending up slightly beyond the can of coke, a visible adjustment to the previous repeated return point of the glass to the table. By her pushing it away, she is establishing it, at this point in the unfolding action, as potentially the last sip from the glass. This is something that does have to be established since unlike B her glass still has more to drink in it. In the greater round of their preparing to leave we can appreciate what $\mathrm{F}$ displays in this gesture, that she has noticed that $\mathrm{B}$ has finished her coffee and is now making available to B that they are potentially both finished with their drinks.

What $\mathrm{B}$ and $\mathrm{F}$ put in place earlier was a possible ending, yet much like the closing sequences of phonecalls, the closing sequence can be abandoned and further talk can ensue. Which it does. The conversation about colleagues and trouble at their work is too good. While it seemed like it was all over for the drinks, B has a "reserve" glass of water that she can now pick up. Given that it is another unfinished drink, the half-filled glass projects forward another stretch of time that it will take to finish it. We might think of this as a reversal of the Arabian Nights phenomenon where in the original the endless supply of stories prevented the death of the heroine, here so long as there are drinks to be drunk then the stories can continue to be told.

Their conversation continues until:
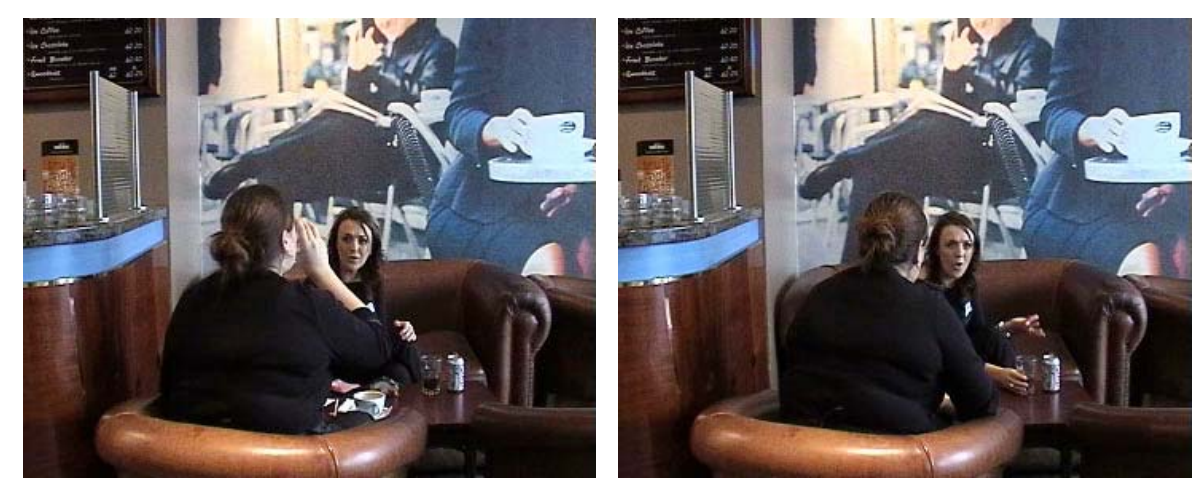

\section{F: Do you [] know what I mean}

F: Do you know what I mean, I

((B’s glass vvvvvvvvvvvvvvvvv)) ((“tap”))

B: ((nods))

\section{((F looks obliquely across B's shoulder))}

\section{F: [] I'm saying no}

\section{B: Yeah}

Once again, in the above transcript, B is draining the last mouthfuls from a glass. This time around $\mathrm{F}$ is in the middle of securing a response from $\mathrm{B}$ to her point. The drink and the talk slightly out of synch, we find F repeating her request "do you know I mean" 
until she secures a nod from B. With the nod of acceptance and continuance, F drops her direct eye contact with B. A method for continuing her point until she looks once again at $\mathrm{B}$. Note also that this time she is not glancing out the window as she did last time, rather she is simply looking slightly to one side of B. In this case her removal of eye contact is directed toward keeping the turn at talk. Not also that B touches the glass on the table with only a tap rather than a clunk.
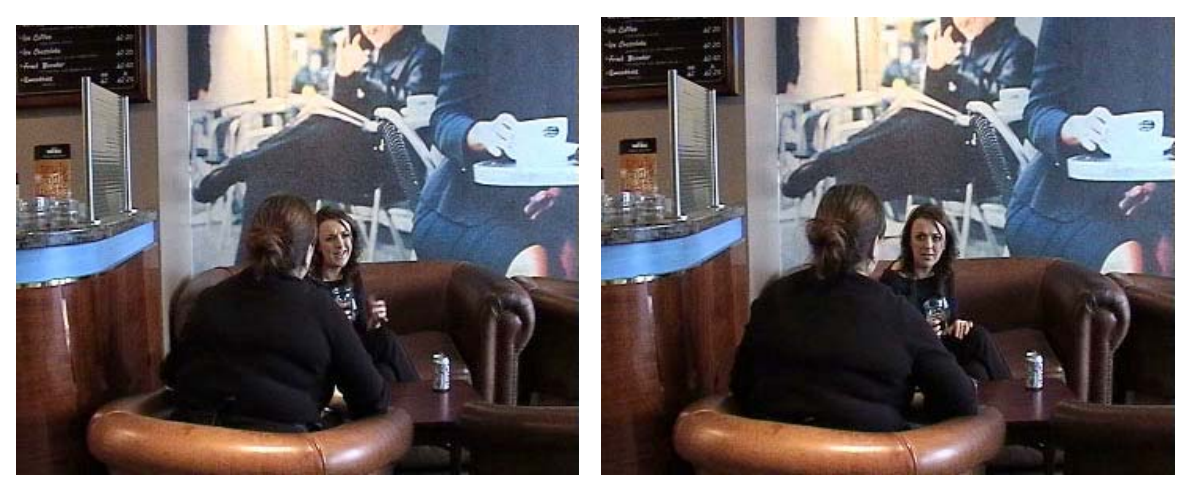

\section{F: ((picks up glass while gesticulating with other hand)) No one's heading it. It's really [] terrible what's going on. ((shaking her head)) [] Do you know what I mean.}

\section{B: ((nods)) \\ F: Definitely dreadful}

F uses two runs to build up the secure B's assessment of F's closing explanation and then evaluation of the trouble at their work that "no one's heading it". Her first assessment of the lack of leadership that 'it's terrible' is further emphasized by her shaking her head. Following a nod of agreement from B, F offers one final mild upgrade by way of concluding the matter: 'definitely dreadful'. Once again though her drinking up is put to good use in further orchestrating her closing remarks, on their trouble at work, picking up her glass of coke as the begins winding up (see still 1 above) which once lifted, then hovers (see still 2 above), waiting for her to take that last anticipated sip. B's attention is doubley secured waiting for the last sip and the last remark.
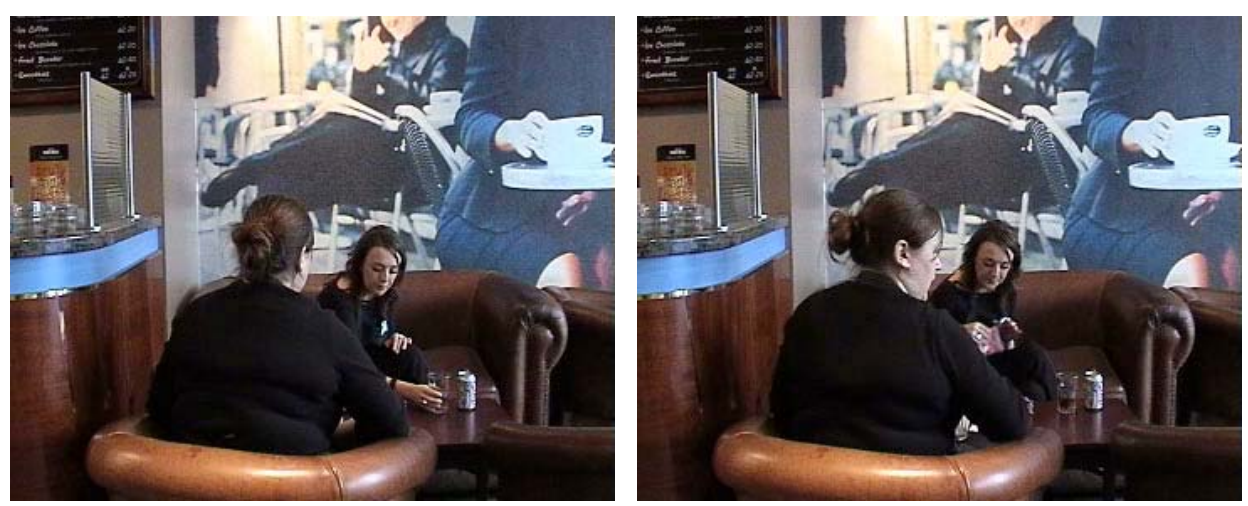

\section{F: ((glass to mouth and drinks-vvvvvvvvvvvvvvv)) (( [] "CLUNK" ))}




\section{F: ((slaps knee)) ((looks down)) Will we get back ((reaches for handbag))}

\section{B: [] ((Looks sideways))}

Just after banging the glass down on the table, F taps her thigh (see Still 1 above), and while she still has the gestural turn (as it were) she takes a hold of her handbag while saying 'will we get back' (see Still 2). At this point they get up in almost perfect synchrony and leave the café. The achievement of this simultaneous lift-off from their seats is laid down in the lead-up to it which happens in a number of steps - the clunk of the glass, the tap of the thigh, the pick up of the bag (see above) and then the leaning back in the chairs (see below). What we end up with is a close timing of leaving their seats which is akin to that of people speaking together putting the phone down at the same time.

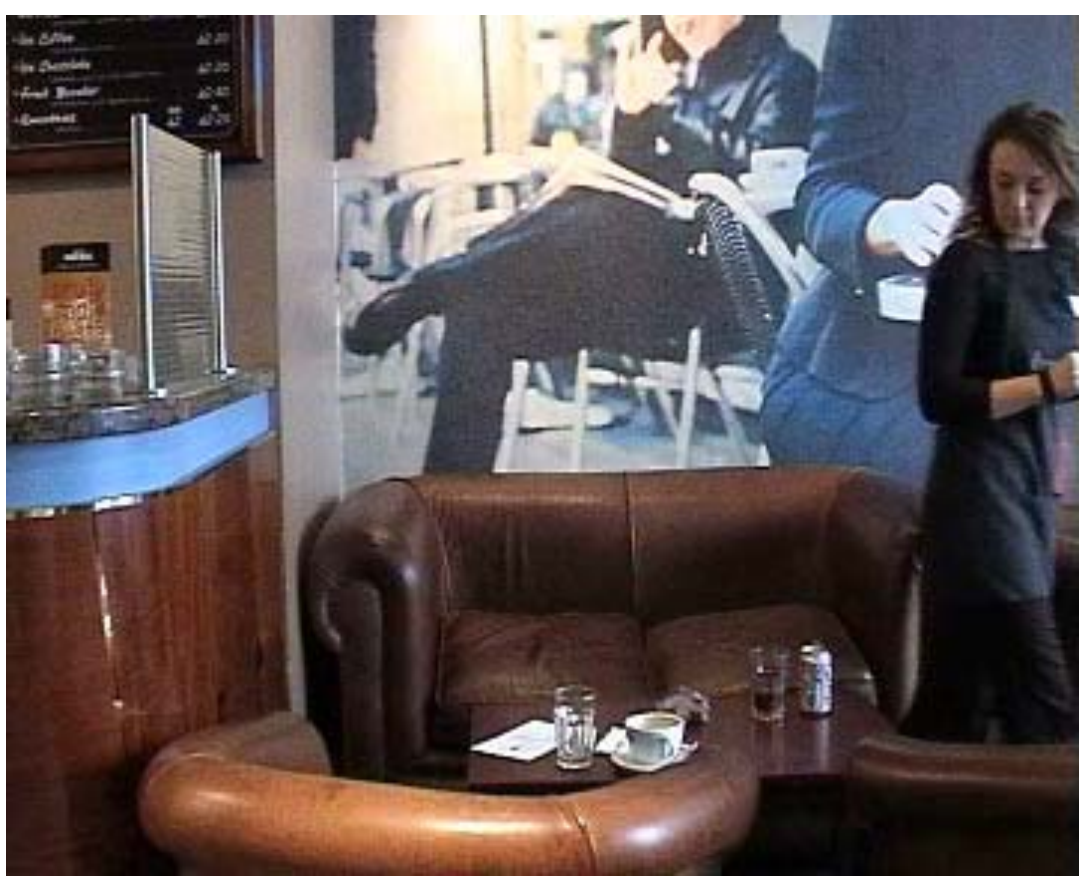

((both lean back, swing forward in chairs in synch, rise, look down, arrange themselves, begin walking and $\mathrm{F}$ takes last look at tabletop []))

What greater consequence does the closely timed ending have for the conversationalists? If we consider what happens when one of them gets up first. It raises the question of whether that one is hurrying the other along. Or for the one that gets up and the other remains seated whether the one sitting is making the first wait on them. These are perhaps inferences that could be made from grosser gaps between them rising up from their chairs. It was notable how finely in time the two women were. In one sense there is an economy to these movements in that if we do keep in time there is no need for additional and accountable adjustments. What we notice though when we are with others where we repeatedly miss-time what should be joint moves with them is perhaps a certain lack of intimacy. A certain discomfort. We note that we bump into one another when trying to walk along the pavement together. Or that the we put the phone down on 
one another. These moments of ordinary disruption begin to lead us into questioning what the nature of our togetherness is with the other and whether there may be some other problem with our relationship.

To return to the issue with which we began, we have seen then through a detailed description of one café visit ending how the very fact of drinking, rather than what substance people are drinking, eases the conversation along. In particular here we have seen how the last sips are involved in the last remarks on a conversation on a particular topic. There is no mechanical determinacy here as we have seen how one potential ending of both drinks and topic can be artfully extended by the conversationalists. Alongside this it has hopefully become apparent how the movements and objects that accompany drinking become resources in talking together. As noted earlier in his work on gesture and stance Goodwin (2007) has brought out very nicely how stance is manifest in a number of ways interaction: positioning oneself to 'see, feel and in other ways perceive as clearly as possible, and in ways relevant to the activities present', related to this first point that stance displays and secures one's epistemic stance and finally that through display of cooperation (or not) moral and affective stances come into play. The majority of Goodwin's work focuses on learning or apprenticeship situations, where the conversation and gestures are linked to a workplace with its environment and tools. What has been intriguing here is to bring that to bear, as I did in the transcripts and their analysis, on an environment and set of things with no sense of common task nor relationships instructor and apprentice.

\section{Closing Remarks}

We have not had the space in this article, nor is there space in the world, for the documentation of the particular sorts of conversation that cafés support. There are almost endless possibilities. If we imagine a list of things we could not do in the café: teaching archeology, bedtime stories for children, trial by jury, running a nuclear power plan. Having thought of such a list I find myself picturing archeologists taking their tutorials in cafés. Mothers with babies in buggies reading them a story to send them to sleep while their vente latte sits on the café table beside them. The staff of the nuclear power plant nipping round to their local Starbucks to talk over sensitive staffing issues. I am are stretching the point here but what I am stretching it toward is the encompassing nature of the café which begins to open out away from political debate, or inquiry into government as a primary function, toward a multitude of conversations.

One of the ideas that has been suggested to me by a fellow researcher is that what might be distinctive about going for a coffee in the café is that it might be an occasion without 'a' reason, thus, unlike the telephone call with its ever-present 'reason for calling' (Sacks 1992). The lack of any particular intention over and above having some refreshment and conversation gives us the possibility for unmotivated talk. Benhabib (1992) puts this nicely in terms of talk with no particular agenda, yet even there, it will be underlain with conceptions of the good life and debate. While, yes I am happy to accept that those conversations do happen, is being at the café part of what constitutes the good life itself? A necessary part of that is reflection on what is good (or bad) about the café, something which visitors of Starbucks have found themselves doing more than most (Raffel, 2004).

What I have dealt with only obliquely until now is the passion that is being expressed in the F \& B's analysis of the troubles of their workplace that we have observed through 
the transcripts and still images. A passion which returns us Stanley Cavell's responses to J L Austin's work on performative speech where he examines the importance of the perlocutionary. For Cavell as for Wittgenstein there is a sense of the importance of "our noting an almost suppressed wince, or a hairbreadth hesitation, or things not essentially different from these, are all we go on in our supposed certainties about each other's suffering, or joyfulness, or distance" (Cavell, 2005: 115). What drinking and talking together in the café gave $\mathrm{B}$ and $\mathrm{F}$ and offers to us as one of its many possibilities is an activity and arrangement that are good for noting those winces and hesitations. Good because in the seating arrangements and the nearness of the things that we have there, the well-worn seats, the cups and the tables, we can focus on one another. Apprehend and respond to one another's expressions of affect and emotion in ways that are hard to imagine were we busily engaged in preparing food for dinner together or equally without the special scrutiny of intimates that are naked with and to one another. "That expressions of emotion excite emotion is an important fact about the working of passionate utterance' (ibid: 179). And so it is with those in our conversation in the cafe that they do indeed excite one another's emotions over their colleagues and their troubles. With or without its caffeine the café is a place where we can be excited by others, their opinions, their knowledge, their stories and more. Where we can show our standing with others, where we can single out or be singled out by others and more. 


\section{Appendix}

[hi]

$+$

[hello]

overlapping speech/gestures

pauses in seconds

it was today

speaker emphasis

((hand goes up))

non-verbal actions

$((\mathrm{vvvvv}))$

downward motion

$((\wedge \wedge \wedge \wedge \wedge))$

upward motion

[]

point where video frame relates to transcript 
Amin, A. and Thrift, N., 2002. Cities: Re-imagining the Urban. Cambridge, Polity. Austin, J.L., 1956-7. A Plea for Excuses, Proceedings of the Aristotelian Society Transcribed into hypertext by Andrew Chrucky (http://www.ditext.com/austin/plea.html).

Baggini, J., 2004, 'Feeling pure won't help the world's poor', Guardian, Manchester.

Balthasar, L. and Mondada, L., 2005. Multiscope video and the continuous access to relevant details, paper given at Interacting Bodies, Lyons 2005. copies available from the authors.

Benhabib, S., 1992. Models of public space: Hannah Arendt, the liberal tradition, and Jürgen Habermas. In: Calhoun, C. (ed.), Habermas and the Public Sphere, London, MIT Press, pp. 73-98.

Blum, A., 2003. The Imaginative Structure of the City. Montreal \& Kingston, McGillQueen's University Press.

Carlin, A.P., 2003. Pro forma arrangements: the visual availability of textual artefacts, Visual Studies 18 (1), 6-20.

Cavell, S., 2002. Must we mean what we say (Updated Edition). Cambridge, Cambridge University Press.

Cavell, S., 2005. Philosophy the day after tomorrow. Belknap Harvard, Harvard.

Cowan, B., 2005. The Social Life of Coffee: The Emergence of the British Coffeehouse. London, Yale University Press.

Crabtree, A., 2000. Remarks on the social organisation of space and place, Journal of Mundane Behaviour 1 (1), http://www.mundanebehaviour.org/issues/v1n1/crabtree.html.

Ellis, M., 2004. The Coffee-house: A Cultural History. Cambridge, Cambridge University Press.

Fish, S., 2007, 'Getting Coffee Is Hard to Do', New York Times (Late Edition Edition), New York.

Garfinkel, H., \& Sacks, H., 1986. On Formal Structures of Practical Actions. In: Garfinkel, H. (ed.), Ethnomethodological Studies of Work, London, Routledge and Keegan Paul, pp. 160-193.

Garfinkel, H. and Wieder, D.L., 1992. Two Incommensurable, Asymmetrically Alternate Technologies of Social Analysis. In: Watson, G. and Seiler, R.M. (eds.), Text in Context: Contributions to Ethnomethodology, London, Sage, pp. $175-206$

Goodwin, C., 2007. Participation, stance and affect in the organization of activities Discourse \& Society 18 (1), 53-73.

Habermas, J., 1989. The Structural Transformation of the Public Sphere, An Inquiry into a Category of Bourgeois Society. Oxford, Polity Press.

Heath, C. and vom Lehn, D., 2004. Configuring reception: looking at exhibits in museums and galleries, Theory, Culture \& Society 21 (6), 45-63.

Laurier, E., 2005a, 'One or several cafes, field report 2', Glasgow \& Edinburgh, University of Glasgow \& University of Edinburgh.

Laurier, E., 2005b, 'What customers do, field report 3', Glasgow, University of Glasgow.

Laurier, E. and Philo, C., 2006. Natural Problems of Naturalistic Video Data. In: Knoblauch, H., Raab, J., Soeffner, H.-G. and Schnettler, B. (eds.), Video- 
analysis: Methodology and Methods, Qualitative Audiovisual Data Analysis in Sociology, Oxford, Peter Lang, pp. 183-192.

Laurier, E. and Philo, C., 2007. 'A parcel of muddling muckworms': revisiting Habermas and the Early Modern English coffee-houses, Social and Cultural Geography, nyp.

Laurier, E., Whyte, A. and Buckner, K., 2002. Neighbouring as an occasioned activity : "Finding a lost cat", Space and Culture 5 (4), 346-367.

Levinson, S.C., 1983. Pragmatics Cambridge, Cambridge University Press.

Livingston, E., 1987. Making Sense of Ethnomethodology. London, Routledge \& Kegan Paul.

Luff, P., Hindmarsh, J. and Heath, C., (eds.) 2000. Workplace Studies, Cambridge University Press, Cambridge.

Lynch, M., 1993. Scientific practice and ordinary action: ethnomethodology and social studies of science. Cambridge, Cambridge University Press.

Lynch, M., 1997, 'The Ethnomethodological Foundations of Conversation Analysis', Ethnomethodology, an improbable sociology?, Cerisy-la-Salle, France.

Lynch, M. and Bogen, D., 1996. The Spectacle of History: Speech, Text and Memory at the Iran-contra Hearings. London, Duke University Press.

Lynch, M., Livingston, E. and Garfinkel, H., 1983. Temporal Order in Laboratory Work. In: Knorr-Cetina, K. and Mulkay, M. (eds.), Science Observed, London, Sage, pp. 205-238.

Mondada, L., 2006. Video recording as the reflexive preservation and cofiguration of phenomenal features for analysis. In: Knoblauch, H. and Schnettler, B. (eds.), Video Analysis: Methodology \& Methods, Oxford, Peter Lang, pp. 51-68.

Mondada, L., forthcoming-a. Deixis spatiale, gestes de pointage et formes de coordination de l'action. In: Barberis, J.-M. and Manes-Gallo, M.C. (eds.), Verbalisation de l'espace et cognition situee: la description d'itineraires pietons, Paris, Editions CNRS.

Mondada, L., forthcoming-b. Video recording practices and the reflexive constitution of the interactional order: some systematic uses of the split-screen technique Human Studies.

Oldenberg, R., 1997. The Great Good Place and how they get you through the day. San Francisco, Marlowe \& Co.

Perec, G., 1999. Species of space and other pieces. London, Penguin.

Phillips, C., 2001. Socrates café: a fresh taste of philosophy. New York, W W Norton \& Co.

Pratt, A., 2002. Hot jobs in cool places. The material cultures of new media product spaces: the case of South of the Market, San Francisco, Information, communication \& society 5 (1), 27-50.

Putnam, R.D., 2000. Bowling alone : the collapse and revival of American community. New York, Simon and Schuster.

Raffel, S., 1979. Matters of Fact. London, Routledge \& Kegan Paul.

Raffel, S., 2004. Baudrillard on Simulations: An Exegesis and a Critique, Sociological Research Online 9 (2), http://www.socresonline.org.uk/9/2/raffel.html.

Schegloff, E., 1992. Introduction. In: Sacks, H. (ed.), Lectures on Conversation, Oxford, Blackwell, pp. ix-lxii.

Schegloff, E.A., 1972. Sequencing in Conversational Openings. In: Gumperz, J.J. and Hymes, D. (eds.), Directions in Sociolinguistics: The Ethnography of Communication, New York, Holt, Rhinehart \& Winston, pp. 346-80. 
Schegloff, E.A., 2007. Sequence Organization in Interaction: Volume 1: A Primer in Conversation Analysis. Cambridge, Cambridge University Press.

Schegloff, E.A. and Sacks, H., 1973. Opening up closings*, Semiotica 8 (4), 289-327. Sudnow, D., 1972. Temporal Parameters of Interpersonal Observation. In: Sudnow, D. (ed.), Studies in Social Interaction, New York, Free Press, pp. 259-279.

te Molder, H. and Potter, J., (eds.) 2005. Conversation and Cognition, Cambridge University Press, Cambridge.

Van Horn Melton, J., 2001. The Rise of the Public in Enlightenment Europe. Cambridge, Cambridge University Press.

Wakeford, N., 2003. The embedding of local culture in global communication: independent internet cafes in London, New Media and Society 5 (3), 379-499. 